\title{
Modeling Impreciseness of Trophic State Levels for Eutrophication Assessment
}

\author{
Tejaswini Dayanand Nalamutt and Subhankar Karmakar
}

\begin{abstract}
Tremendous efforts have been madeto propose numerous indices for quantifyingstates of eutrophication in lentic water bodies over the last decades. Most of the indices are developed or modified considering conventional trophic state indices [e.g., Carlson trophic state index (TSI)] or pre-specified ranges of cause and response variables [e.g., index proposed by Organization of Economic and Cooperation and Development (OECD)], where a strong correlation structure must exist among cause and response variables. Here an attempt is made to model impreciseness or subjectivity of trophic state levels,especially for weakly correlated variables. A generalized framework using fuzzy synthetic evaluation (FSE), analytic hierarchy process (AHP) and the concept of statistical entropyis proposed to assess the trophic state of lentic water bodies. The proposed methodology has been tested with the case study of Jordan lake data set collected from the United States of Geological Survey (USGS) data base.The result shows that, the eutrophication problem is critical mostly during the months of August to October,and the method can efficiently capture the rapid changes in trophic states. The sensitivity of the model has been tested with different weight structures for cause and response variables considered during model development, and the robustness of the model has also been tested with different weighting techniques.
\end{abstract}

Index Terms-Eutrophication, AHP, entropy, FSE, trophic state.

\section{INTRODUCTION}

Eutrophication in lentic water body can be defined with the characteristics of lush vegetation, high concentration of salts and high turbidity [1], considered as wide spread water quality problem in many countries. The eutrophication process is complex in nature with many cause (mainly nutrients) and response variables (e.g., chlorophyll-a), hence it is multidimensional and requires multivariate analysis for assessment. In this regard, many multivariate indices have been developed [2], [3].Carlson [3] TSI is considered as simplest and commonly applied method, but it can give different trophic index values for the parameters (Chlorophyll-a, Total Phosphorous and Secchi Depth) when applied simultaneously. Apart from this, averaging of all

Manuscript received April 15, 2013; revised July 2, 2013.

Tejaswini Dayanand Nalamuttis is with the Centre for Environmental Science and Engineering, Indian Institute of Technology Bombay, Mumbai, India (e-mail: tejudn@gmail.com).

Subhankar Karmakaris is with the Centre for Environmental Science and Engineering, Indian Institute of Technology Bombay. $\mathrm{He}$ is also an associated faculty: Interdisciplinary Program in Climate Studies, Indian Institute of Technology Bombay, Mumbai, India (e-mail: skarmakar@iitb.ac.in). three indices may give inconsistent results [4], which may affect in the decision making of water quality management programs. As per Wang [5] trophic state classifications are to be fuzzy around their boundaries and the relationships between the parameters are known to be uncertain. There is need to develop the models which can take care of such uncertainties.

Fuzzy set theory was introduced by Zadeh [6], which incorporates the specification of uncertainty by membership functions. Silvert [7] showed the application of fuzzy method to develop environmental indices. The suggested method has extensive applications in water quality management, where, majority of the applications are based on FSE technique [8]-[12].Several methods are available (e.g., AHP, entropy, equal weight method, etc.) to choose set of appropriate weights in FSE technique. The selection of method for weighting and selection of appropriate weights for attributes (in the present study, the cause and response variables form the set of attributes) play an important role in FSE. The AHP is one of the most widely used multi-attribute decision making (MADM) method for weight elicitation, which wasfirst proposed by T.L.Saaty [13].The application of AHP is based on subjective importance provided by the experts to different attributes. Another level of uncertainty may be introduced in the problem due to randomness and variability of the attribute data, and the concept of entropy [14] is involved to address the randomness of cause and response variables in the trophic state classification. Entropy is a measure of uncertainties of random variables; larger entropy value indicates more randomness, resulting less information content [15], [16]. In the present study, the proposed methodology based on FSE, AHP and concepts of entropy is applied on a sampling site of Jordan lake (station no. 209699999), USA [17].

\section{Methodology}

In the current study, FSE technique, AHP and the statistical entropy method are used to propose the framework for the assessment of eutrophication in lentic water bodies.

\section{A. Classification Criteria}

Organization of Economic and Cooperation and Development (OECD) index [18] is used forthe classification of trophic state. Considerable overlap between the ranges of trophic indicators (set of cause and response variables) for different trophic states can be addressed through the concept of fuzzy sets. 


\section{B. Selection of Indicators for Trophic State Assessment}

The efficiency of trophic state index in classifying the trophic state of water body mainly depends on the indicators used in the index construction. Commonly used trophic state indicators are, nutrients, Chlorophyll-a (Chl-a), Secchi depth (SD) etc. In lentic water bodies, algal densities can be controlled by the limiting nutrients and the limiting nutrient can be found based on the N/P ratio. Typically in fresh water systems phosphorous is the limiting nutrient, but should not be taken to mean that phosphorous is the only limiting nutrient which limits the productivity in all water bodies [19]. Researchers found that a co-limitation of primary productivity by nitrogen and phosphorous is common in lakes [20]. In such situations, consideration of nutrients likes TN, TP towards the trophic state classification methodologies would be more appropriate. Recently secchi depth has been dropped from the TSI calculations in Florida County [21] as transparency is often reduced due to naturally occurring dissolved organic matter. In the current study Total Nitrogen (TN), Total Phosphorous (TP) and Chlorophyll-a (Chl-a) are considered in the analysis for the classification of trophic state.

\section{Fuzzy Membership Functions}

TABLE I: TROPHIC STATE ClASSIFICATION AS PROPOSED By OECD

\begin{tabular}{lllllll}
\hline \multirow{2}{*}{$\begin{array}{l}\text { Trophic } \\
\text { Indicator }\end{array}$} & \multicolumn{2}{l}{ Oligotrophic } & \multicolumn{2}{l}{ Mesotrophic } & \multicolumn{2}{l}{ Eutrophic } \\
\cline { 2 - 7 } & Range & Mean & Range & Mean & Range & Mean \\
\hline $\begin{array}{l}\text { Chl-a } \\
(\mu \mathrm{g} / \mathrm{L})\end{array}$ & $0.3-4.5$ & 1.7 & $3-11$ & 4.7 & $2.7-78$ & 14.3 \\
\hline $\begin{array}{l}\mathrm{TP} \\
(\mu \mathrm{g} / \mathrm{L})\end{array}$ & $3-17.7$ & 8 & $10.9-95.6$ & 26.7 & $16.2-386$ & 84.4 \\
\hline $\mathrm{TN}(\mu \mathrm{g} / \mathrm{L})$ & $\begin{array}{l}307-163 \\
0\end{array}$ & 661 & $\begin{array}{l}361-138 \\
7\end{array}$ & 753 & $\begin{array}{l}393-610 \\
0\end{array}$ & 1875 \\
\hline
\end{tabular}

In OECD index (Table I), the trophic states defined are having overlapping of the ranges and are considered as fuzzy zones. These ranges are considered as criteria to set fuzzy input data. For three trophic levels such as eutrophic, mesotrophic and oligotrophic, fuzzy sets are defined by triangular and trapezoidal membership functions, as shown in Fig. 1. In this study based on OECD index, three membership functions for three indicators (TN, TP and Chl-a) are defined as per "(1)".

$$
\begin{aligned}
& f_{e}(x)=\left\{\begin{array}{cc}
1 & x \geq c \\
(x-b) /(c-b) & b<x<c \\
0 & x \leq b
\end{array}\right\} \\
& f_{m}(x)=\left\{\begin{array}{cc} 
\\
0 & x \geq c \\
(c-x) /(c-b) & b<x<c \\
(x-a) /(b-a) & a<x \leq b \\
0 & x \leq a
\end{array}\right\} \\
& f_{o}(x)=\left\{\begin{array}{cc}
0 & x \geq b \\
(b-x) /(b-a) & a<x<b \\
1 & x \leq a
\end{array}\right\}
\end{aligned}
$$

where $f$ is the membership function and the subscripts $e, m$ and $o$ stand for eutrophic, mesotrophic and oligotrophic conditions and $x$ is the input value of the data set for all three indicators considered in this study. Table II indicates $a, b$ and $c$ values of different trophic indicators considered in this study. From Fig. 1 the membership values of $a, b$ and $c$ for each fuzzy set of TN, TP and Chl-a, can be written as:

for eutrophic condition:

$f_{e}(b)=0$ and $f_{e}(c)=1$;

for mesotrophic condition:

$f_{m}(a)=0, f_{m}(b)=1$ and $f_{m}(c)=0$

for oligotrophic condition:

$f_{o}(a)=1$ and $f_{o}(b)=0$

As shown in Fig. 1, higher values of TN, TP and Chl-a, indicates higher level of eutrophic condition.

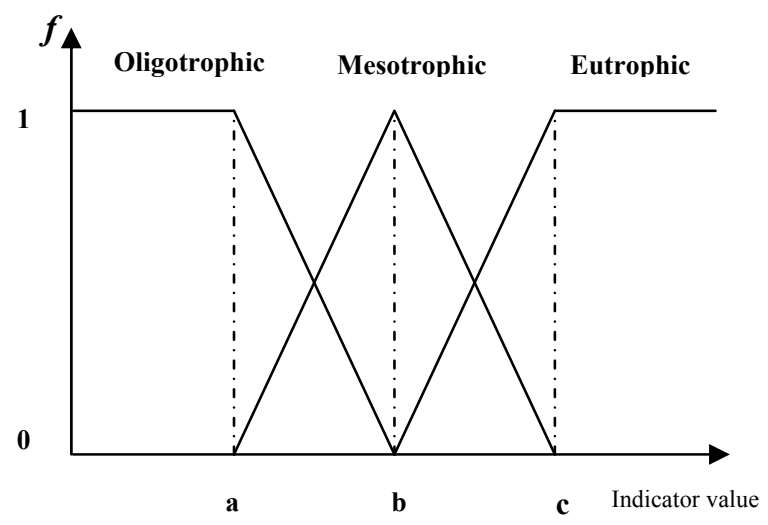

Fig.1. Membership function of trophic state indicators.

TABLE II: Key PoINTS DEFINING FuZZY LIMITS OF MEMBERSHIP FUNCTIONS

\begin{tabular}{lccc}
\multicolumn{4}{c}{ FUNCTIONS } \\
TrophicIndicator & $\begin{array}{c}\text { a } \\
\text { (Oligotrophic) }\end{array}$ & $\begin{array}{c}\text { b } \\
\text { (Mesotrophic) }\end{array}$ & $\begin{array}{c}\text { c } \\
\text { (Eutrophic) }\end{array}$ \\
\hline Chl-a $(\mu \mathrm{g} / \mathrm{L})$ & 1.7 & 4.7 & 14 \\
\hline $\mathbf{T P}(\mu \mathrm{g} / \mathrm{L})$ & 8 & 27 & 84 \\
\hline $\mathbf{T N}(\mu \mathrm{g} / \mathrm{L})$ & 661 & 753 & 1875 \\
\hline
\end{tabular}

\section{Construction of Membership Matrix}

"The membership matrix $(R)$ for TN, TP and Chl-a are formed using (1)". In membership matrix (R) the rows will indicate the parameters while column will indicate the trophic states [12].

$$
R=\left[\begin{array}{ccc}
f_{T N, e} & f_{\mathrm{TN}, m} & f_{T N, o} \\
f_{T P, e} & f_{T P, m} & f_{T P, o} \\
f_{\mathrm{Chl}-\mathrm{a}, e} & f_{\text {Chl-a,m }} & f_{\text {Chl-a,o }}
\end{array}\right]
$$

\section{E. Weights for Indicators}

Proper assignment of weights to the indicators is important in the FSE technique [9]. In this study weights obtained from AHP and entropy methods are combined to determine integrated weight. The subjective information obtained by the experts is incorporated by the AHP method while objective information is by the entropy method.

\section{F. Entropy Method}

The concept of entropy is introduced by Shannon [14]. It 
can measure the amount of useful information from the data provided. High entropy value illustrates less useful information while less entropy value provides more useful information; hence entropy theory is an objective way for weight determination [11].

Suppose there are $\mathrm{n}$ evaluating indicators in $\mathrm{m}$ data set and forms original evaluation matrix $(E M)$,

$$
E M=\left[\begin{array}{ccccc}
X_{11} & X_{12} & \cdot & \cdot & X_{1 n} \\
X_{21} & X_{22} & \cdot & \cdot & X_{2 n} \\
\cdot & \cdot & \cdot & \cdot & \cdot \\
\cdot & \cdot & \cdot & \cdot & \cdot \\
X_{m 1} & X_{m 2} & \cdot & \cdot & X_{m n}
\end{array}\right]
$$

The objective information of the $j$ th criteria by the $i$ th alternative is expressed by an element $X_{i j}$ of the evaluation matrix $(i=1,2 \ldots . . m ; j=1,2 \ldots . n)$. The degree of closeness, denoted by $d_{i j}$ of $X_{i j}$ can be defined as (normalization of the elements of original evaluation matrix),

$$
d_{i j=}\left(X_{i j} \div X^{*}{ }_{j}\right) \text { for maximum criterion }
$$

where

$$
\begin{aligned}
& X_{j}^{*}=\max \left\{X_{i j}\right\} \text { for } j^{\text {th }} \text { criteria }(i=1,2 \ldots m) \\
& d_{i j}=\left(X_{j}^{*} \div X_{i j}\right)_{\text {for minimum criterion }}
\end{aligned}
$$

where

$$
X_{j}^{*}=\min \left\{X_{i j}\right\} \text { for } j \text { th criteria }(i=1,2 \ldots . \mathrm{m})
$$

In the current study indicator selected are chlorophyll-a, $\mathrm{TN}$ and TP and the minimum criterion is applied.

As per the above procedure, the value of $d_{i j}$ ranges from 0 to 1 . Define

$$
D_{j}=\sum_{i=1}^{m} d_{i j}
$$

for $j$ th criteria

The probability of the criterion to occur is defined [15] by $p_{i j}$ as,

$$
p_{i j}=d_{i j} / D_{j}
$$

The entropy measurement of the $j$ th criteria

$$
e_{j}=-c \sum_{i=1}^{m} p_{i j} \ln \left(p_{i j}\right)
$$

where

$$
c=1 / \ln (m)>0 \text { and } e_{j} \geq 0
$$

Total entropy is defined as,

$$
e=\sum_{j=1}^{n} e_{j}
$$

The objective weight of the $j$ thcriteria, $\lambda_{j}$ is defined as

$$
\lambda_{j}=\frac{1-e_{j}}{\sum_{j=1}^{n} 1-e_{j}}
$$

where

$$
0 \leq \lambda_{j} \leq 1 ; \text { and } \sum_{j=1}^{n} \lambda_{j}=1
$$

\section{G. Analytic Hierarchy Process (AHP)}

AHP is a commonly applied technique in many decision making environments, which was developed by Saaty [13]. The subjective importance of the indicators involved in the analysis, are calculated by the pair wise comparison matrix (PCM) based on the expert's judgment. The Chlorophyll-a is considered as most important factor in trophic state assessment and phosphorous is the second. In water bodies co-limitation by phosphorous and nitrogen is common, in that case the weight assignment towards TN and TP should be done carefully and the matrix is developed in such a way that

$$
W=\left(w_{1}, w_{2}, \ldots . . w_{n}\right)
$$

where

$$
\sum_{j=1}^{n} w_{j}=1 ; \quad(j=1,2 \ldots n)
$$

\section{H. Integrated Weight (S)}

Subjective weights determined by the AHP and the objective weight determined by the entropy methodcan be combined to form an integrated weight [16].

$$
\text { Integrated weight }\left(\mathrm{S}_{j}\right)=\frac{\lambda_{j} w_{j}}{\sum_{j=1}^{n} \lambda_{j} w_{j}}
$$

The classification of trophic state is determined by the matrix operation of the integrated weight vector with fuzzy matrix and shown as,

$$
\text { Trophic state }(B)=S \times R=\max \left[\begin{array}{lll}
b_{e} & b_{m} & b_{o}
\end{array}\right]
$$

The maximum membership value corresponding to eutrophic $\left(b_{e}\right)$, mesotrophic $\left(b_{m}\right)$ or oligotrophic $\left(b_{o}\right)$ can be taken as the trophic state of the water body.

\section{APPLICATION}

To examine the potential of the proposed methodology, two years (2008-2009) bi-monthly data set $(n=12)$ consists of Total Nitrogen (TN), Total Phosphorous (TP) and chlorophyll-a, for a sampling site (station no. 209699999) of Jordan lake, North Carolina, USA is collected from the USGS data base. For further information, USGS site [17] can be referred. 


\section{REsults AND DisCUSSION}

AHP method is adopted to determine the subjective importance of the indicators with the help of three experts in the field related to water quality. The importance of the indicators is based on three levels as equal, moderate and strong with numerical assignment as 1,2 and 3 respectively. The combined pair wise comparison matrix $(T)$ for the indicators is given in "(16)". The inconsistency ratio [13] found to be 0.0 (less than $10 \%$ ) showing the acceptable range of judgment. The objective weights calculated by entropy method and the subjective weights obtained by the AHP methods are summarized (Table III).

$$
T=\begin{array}{ccc}
T N & T P & C h l-a \\
T N & T P \\
C h l-a & {\left[\begin{array}{ccc}
1 & 0.55 & 0.33 \\
1.82 & 1 & 0.55 \\
3.0 & 1.82 & 1
\end{array}\right]}
\end{array}
$$

TABLE III: OBJECTIVE WEIGHTS AND SUBJECTIVE WEIGHTS OF PARAMETERS

\begin{tabular}{cccccc}
\multicolumn{4}{c}{ PARAMETERS } \\
\hline$\lambda_{\text {TN }}$ & $\lambda_{\text {TP }}$ & $\lambda_{\text {Chl-a }}$ & W $_{\text {TN }}$ & w TP & W $_{\text {Chl-a }}$ \\
\hline 0.012 & 0.033 & 0.953 & 0.170 & 0.300 & 0.520 \\
\hline
\end{tabular}

"The integrated weights are calculated using (14)" and shown as,

$$
\begin{aligned}
\text { Integrated weights } & =\left(S_{T N}, S_{T P}, S_{C h l-a}\right) \\
& =(0.004,0.019,0.97) ?
\end{aligned}
$$

\begin{tabular}{|c|c|c|c|c|c|c|c|c|c|}
\hline Date & TSI (TP) & TSI(Chl-a) & TSI(SD) & TSI (Average) & Trophic State & $\begin{array}{l}\text { Membership } \\
\text { value }\left(b_{e}\right)\end{array}$ & $\begin{array}{l}\text { Membership } \\
\text { value }\left(b_{m}\right)\end{array}$ & $\begin{array}{l}\text { Membership } \\
\text { value }\left(b_{o}\right)\end{array}$ & $\begin{array}{l}\text { Trophic } \\
\text { state }\end{array}$ \\
\hline Feb-08 & 65.41 & 44.68 & 55.15 & 55.08 & $\mathrm{E}$ & 0.016 & 0.821 & 0.163 & M \\
\hline Apr-08 & 69.35 & 45.78 & 65.14 & 60.09 & $\mathrm{E}$ & 0.021 & 0.979 & 0 & M \\
\hline Jun-08 & 70.41 & 64.19 & 65.14 & 66.58 & E & 0.997 & 0.003 & 0 & $\mathrm{E}$ \\
\hline Aug-08 & 69.97 & 65.25 & 63.22 & 66.14 & $\mathrm{E}$ & 0.997 & 0.003 & 0 & $\mathrm{E}$ \\
\hline Oct-08 & 62.7 & 64.38 & 61.52 & 62.87 & $\mathrm{E}$ & 0.988 & 0.012 & 0 & $\mathrm{E}$ \\
\hline Dec-08 & 74.56 & 46.19 & 77.35 & 66.03 & $\mathrm{E}$ & 0.032 & 0.968 & 0 & M \\
\hline Feb-09 & 63.43 & 43.17 & 58.63 & 55.07 & $\mathrm{E}$ & 0.015 & 0.627 & 0.358 & M \\
\hline Apr-09 & 69.2 & 63 & 65.14 & 65.78 & $\mathrm{E}$ & 0.997 & 0.003 & 0 & $\mathrm{E}$ \\
\hline Jun-09 & 70.7 & 58.28 & 65.14 & 64.71 & $\mathrm{E}$ & 0.997 & 0.003 & 0 & $\mathrm{E}$ \\
\hline Aug-09 & 72.82 & 64.19 & 67.36 & 68.12 & $\mathrm{E}$ & 0.998 & 0.002 & 0 & $\mathrm{E}$ \\
\hline Oct-09 & 66.02 & 65.89 & 63.22 & 65.04 & $\mathrm{E}$ & 0.994 & 0.006 & 0 & $\mathrm{E}$ \\
\hline Dec-09 & 67.34 & 28.41 & 69.99 & 55.25 & $\mathrm{E}$ & 0.02 & 0.004 & 0.976 & $\mathrm{O}$ \\
\hline
\end{tabular}

\begin{tabular}{cc}
\multicolumn{2}{c}{ TABLE IV: TROPHIC STATE INDEX (CARLSON 1977) } \\
\hline TSI value & Trophic Class \\
\hline$<40$ & Oligotrophic (O) \\
\hline $40-50$ & Mesotrophic (M) \\
\hline $50-70$ & Eutrophic (E) \\
\hline $70-100$ & Hyper eutrophic (HE) \\
\hline
\end{tabular}

TABLE V: COMPARISON OF RESUltS OF TROPHIC STATE ClASSIFICATION AS PER CARLSON [3] AND THE CURRENT METHODOLOGY

The results of entropy show that, Chlorophyll-a gives highest amount of usable information with least entropy value and TN gives least amount of usable information with highest entropy value. As initially stated chlorophyll-a is considered as important parameter in trophic state assessment the integrated weight achieved by this parameter is highest in the present analysis and followed by the phosphorous. The changes in the eutrophication levels are mainly determined by the chlorophyll-a in Jordan lake.

Carlson TSI is commonly applied method to determine the trophic state, which is based on the three indicators (chl-a, TP and Secchi depth) and the trophic state classes are as given in Table IV. Averaging of all these indicesfor the trophic state assessment may not give realistic results and may affect the decision making in the lake management programs [4].

The current analysis result and the comparison with Carlson TSI are given in Table V. According to Carlson index (TSI-chl-a), the Jordan lake is mesotrophic for Feb-2008 period, whereas TSI values obtained from SD and TP will classify the lake in eutrophic condition for the same period. The average TSI value of all these indicators will classify Jordan lake in to eutrophic condition (Fig. 2), where as current results classify the lake in mesotrophic condition in Feb-2008. The Average TSI values obtained from three indicators will classify the Jordan lake in to eutrophic condition throughout the period 2008-2009, where as current results indicate the rapid changes of trophic states during the period of 2008-2009 (Table V).

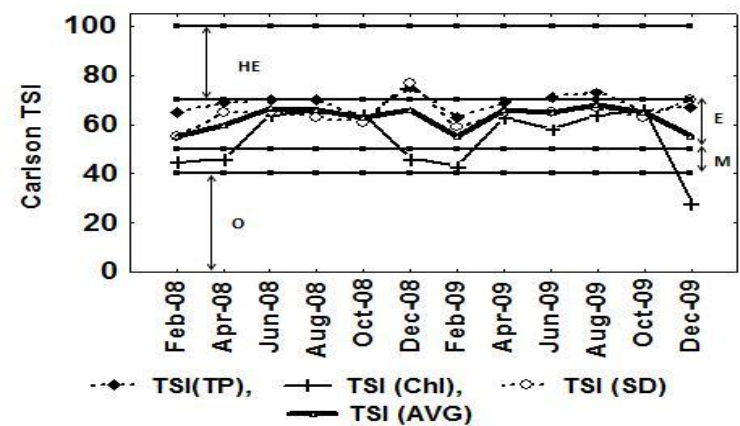

Fig. 2. Trophic state classification (Carlson TSI) Jordan lake, where HE indicates hyper eutrophic, e indicates eutrophic, $\mathrm{M}$ indicates Mesotrophic and $\mathrm{O}$ indicates oligotrophic condition. 


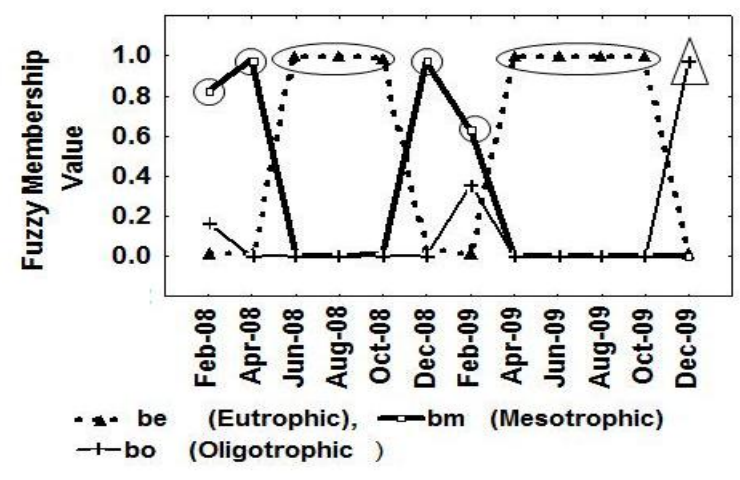

Fig. 3. Membership values of three trophic states of Jordan lake.

Fig. 3 shows trophic state of Jordan lake for the period of 2008-2009 assigned by the maximum membership value.

The predominating states are shown with different shapes in Fig. 3. For example, the mesotrophic states are shown bycircles (with solid lines), eutrophic states are shown by oval shapes (with solid lines) and oligotrophic condition is indicated by triangular shapes(with solid lines) whose membership values are maximum for the period of 2008-2009.

\section{CONCLUSIONS}

FSE technique in water quality assessment has been practiced extensively since many decades. The appropriate design of weight structure in FSE is important as it would decide the trophic state of lentic water bodies considering the imprecision in the levels of cause and response variables. The present study, addresses uncertainty in human decision for weight selection through AHP, and models the randomness associated with data sets using the concept of entropy. The proposed entropy method considers the information available adequately from input data to determine the weights, while AHP method provides the weights based on the judgments of the experts. The result shows that, the eutrophication problem in sampling site 209699999 of Jordan lake is critical mostly during the months of June to October, and the method can efficiently capture the rapid changes in trophic states. The proposed method is generic and can be applied to any water body for evaluation of trophic states.

\section{REFERENCES}

[1] R. Lu and S. Lo, "Diagnosing reservoir water quality using self-organizing maps and fuzzy theory," Water Research, vol. 36, pp. 2265-2274, 2002.

[2] C. Forsberg and S. Riding, "Eutrophication parameters and trophic state indices in 30 Swedish waste receiving lakes," Archives of Hidrobioogy, vol 89, pp. 189-207,1980.

[3] R. E.Carlson, "A trophic state index for lakes," Limnology and Oceanography, vol. 22, pp.361-369. 1977.

[4] Jordan Lake Management Plan. (August 2006). First Edition. [Online]. pp. 11, Available: http://www.jlrpd.org/lmp/plan2.pdf.

[5] D. Wang, V. P. Singh, and Y. Zhu, "Hybrid fuzzy and optimal modeling for water quality evaluation," Water Resources Research, vol. 43, 2006.
[6] L. A.Zadeh, "Fuzzy sets," Information and Control, vol. 8, issue 3, pp. 338-353, 1965.

[7] W.Silvert, "Fuzzy indices of environmental conditions," EcologicalModelling, vol. 130, pp. 111-119, 2000.

[8] J. Liu, Q. Li, and Y. Wang, "Risk analysis in ultra deep scientific drilling project - A fuzzy synthetic evaluation approach," International Journal of Project Management, vol. 31, issue 3, pp. 449-458, 2013.

[9] J. Wang, L. U. Xiangouo, T. Jinghan, and J. Ming, "Fuzzysynthetic evaluation of water quality of naoli river using parameter correlation analysis," Chinese Geographical Science, vol. 18, issue 4, pp. 361-368, 2008.

[10] S. Dahia, B. Singh, S. Gaur, V. K. Garg, and H. S. Kushwaha, "Analysis of groundwater quality using fuzzy synthetic evaluation," Journal of Hazardous Materials, vol. 147, pp. 938-946, 2007.

[11] Z. Zhihong, Y. Yi, and S. Jing-Nan, "Entropy method for determination of weight of evaluating in fuzzy synthetic evaluation for water quality assessment," Journal of Environmental science, vol. 18, issue 5, pp. 1020-1023, 2006.

[12] R. S. Lu, S. L. Lo, and J.Y. Hu, "Analysis of reservoir water quality using fuzzy synthetic evaluation," Stochastic Environmental Research and Risk Assessment, vol. 13, pp. 327-336, 1999.

[13] T. L. Saaty, Multicriteria decision making: The analytic hierarchy process, University of Pittsburgh, Pittsburgh, 1988.

[14] C. Shannon, "A Mathematical Theory of Communication," Bell System Technical. Journal, vol. 27, pp. 379-423, 1948.

[15] M. Zeleny, Multiple criteria decision making, New York: McGraw-Hill.

[16] S. Chowdhury and T. Husain, "Evaluation of drinking water treatment technology: an entropy-based fuzzy application," Journalof Environmental Engineering, vol. 132, pp. 1264-1271, 2006.

[17] USGS water data for the nation. [Online]. Available: http://waterdata.usgs.gov/nwis

[18] OECD.

[Online].

Available: http://www.chebucto.ns.ca/ccn/info/Science/SWCS/TPMODELS/OE CD/trophic.html\#table-3

[19] W. K. Dodds, K. R. Johnson, and J. C Priscu, "Simultaneous nitrogen and phosphorous deficiency in natural phytoplankton assemblages: theory, empirical evidence and implications for lake management," Lakes and Reservoir Management, vol. 5, pp. 21-26, 1989.

[20] R. Matthews, M. Hilles, and G. Pelletier, " Determining trophic state in Lake Whatcom, Washington, a soft water lake exhibiting seasonal nitrogen limitation," Hydrobiologia, vol. 468, pp. 107-121, 2002.

[21] Trophic State Index (TSI). Caveats and limitations. [Online]. Available: http://www.hillsborough.wateratlas.usf.edu/shared/leammore.asp?tool section $=1 \mathrm{~m}$ tsi

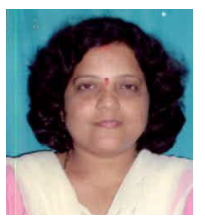

Tejaswini D. Nalamutt holds undergraduate degree in civil engineering, from Karnataka University, Dharwad, and postgraduate degree from Visvesvaraya Technological University, Belgaum, India, in environmental engineering. She is presently pursuing her Ph.D. at Centre for Environmental Science \& Engineering (CESE), Indian Institute of Technology Bombay (IITB), Mumbai, India. Her areas of research include Multivariate statistics, Modeling of Eutrophication assessment, and Water quality analysis of lentic water bodies.

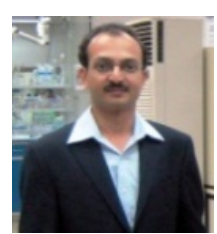

Subhankar Karmakar has obtained Ph.D. degree in water resources and environmental engineering from Indian Institute of Science, Bangalore, India. He is presently an Assistant Professor at Centre for Environmental Science and Engineering (CESE), Indian Institute of Technology Bombay, Mumbai, India. His areas research interests are Simulation and optimization of water resources and environmental systems, Lentic water quality management, Risk Analysis and uncertainty modeling, Decision sciences, Life cycle analysis, Flood risk management. 